\title{
PENGARUH PENDIDIKAN PRAMUKA TERHADAP PEMBENTUKAN KARAKTER RELIGIUS PADA ANGGOTA PRAMUKA
}

\author{
Muhaemin, Aunu Ihwah \\ Institut Agama Islam Negeri Palopo \\ email : muhaemin@iainpalopo.ac.id
}

\begin{abstract}
This study aims to find out, 1) learning outcomes scouting scouting members, 2) the religious character of scout member MI Datok Sulaiman Putra Palopo section, and 3) the influence of scouting education on the formation of religious character of MI Datok Sulaiman part Boy Palopo. This research uses ex post facto research. The result of descriptive statistic analysis shows that the average score of learning scout education result of scout member MI Datok Sulaiman Palopo is 89,4737 from ideal score 100 with standard devias $i=3,95062$ and variance $=15,607$. Highest score (maximum) $=96$ and lowest score (minimum) $=81$. Result of inferential statistic analysis using inferential statistic by using simple linear regression obtained that correlation of $r$ value equal to 0,631 show strong correlation and kofesien determinan equal to $39,8 \%$. This shows that there is a significant influence between scouting education on the formation of religious character of Scout members.
\end{abstract}

Keywords: Scouting Education, Religious Character. Scout Member

\begin{abstract}
Abstrak: Penelitian ini bertujuan untuk mengetahui, 1) hasil belajar pendidikan kepramukaan anggota pramuka, 2) karakter religius anggota pramuka MI Datok Sulaiman Bagian Putra Palopo, dan 3) pengaruh pendidikan kepramukaan terhadap pembentukan karakter religius anggota pramuka MI Datok Sulaiman Bagian Putra Palopo. Penelitian ini menggunakan jenis penelitian ex-post facto. Teknik dokumentasi dengan mengumpulkan data yang bersumber dari arsip. Hasil analisis statistik deskriptif menunjukkan bahwa skor ratarata hasil belajar pendidikan kepramukaan anggota pramuka MI Datok Sulaiman Palopo adalah sebesar 89,4737 dari skor ideal 100 dengan standar devias $\mathrm{i}=3,95062$ dan variansi $=15,607$. Skor tertinggi $($ maksimum $)=96$ dan skor terendah $($ minimum $)=81$. Hasil analisis statistik inferensial dengan menggunakan statistik inferensial dengan menggunakan regresi linear sederhana diperoleh bahwa korelasi nilai $r$ sebesar 0,631 menunjukkan korelasi kuat serta kofesien determinan yaitu sebesar $39,8 \%$. Hal ini menunjukkan bahwa benar terdapat pengaruh yang signifikan antara pendidikan kepramukaan terhadap pembentukan karakter religius anggota pramuka.
\end{abstract}

Kata kunci: Pendidikan Kepramukaan, Karakter Religius, anggota pramuka

\section{PENDAHULUAN}

Ketika peran ilmu pengetahuan dan teknologi dalam menentukan kesejahteraan suatu negara semakin besar, Lembaga-lembaga pendidikan formal diharapkan dapat berkontribusi lebih besar dalam meningkatkan kemampuan suatu bangsa untuk penguasaan ilmu pengetahuan dan teknologi yang terus berkembang pesat. Sehingga, upaya untuk lebih baik 
dalam penguasaan ilmu pengetahuan dan teknologi sering harus dibayar dengan berkurangnya perhatian terhadap pendidikan karakter, oleh karena itu salah satunya pendidikan yang menawarkan nilai-nilai karakter yaitu pendidikan pramuka.

Pengenalan pendidikan kepramukaan kepada anak-anak sejak dini, anak-anak tidak hanya dibentuk karakternya sebagai sosok yang mandiri melainkan juga di didik memahami dan mengimplementasikan baik sikap bertaqwa kepada Tuhan Yang Maha Esa, jujur, berani, kerja keras, dan sisisisi positif lain seperti yang terkandung dalam Dasa Dharma pramuka. Sebagaimana dalam buku Andri

Bob Sunardi disebutkan bahwa dalam undang-undang Republik Indonesia No.12 tahun 2010 tentang Gerakan Pramuka yaitu Gerakan pramuka adalah organisasi yang dibentuk oleh pramuka untuk menyelenggarakan pendidikan kepramukaan. Pramuka adalah warga negara Indonesia yang aktif dalam pendidikan kepramukaan serta mengamalkan Satya pramuka dan Darma pramuka.

Menurut Khairul Ummah kepramukaan berfungsi sebagai: a. Kegiatan yang menarik bagi anak atau pemuda, Kegiatan yang menarik berarti bahwa kegiatan pramuka harus menyenangkan dan mendidik. Oleh karena itu, permainan yang ada dalam gerakan pramuka harus mempunyai tujuan dan aturan, bukan untuk hiburan saja. b. Pengabdian bagi orang dewasa, kepramukaan bukan lagi permainan, tetapi merupakan tugas yang memerlukan keikhlasan, kerelaan dan pengabdian. Orang dewasa mempunyai kewajiban untuk secara sukarela membaktikan dirinya demi kesuksesan pencapaian tujuan organisasi. c. Alat bagi masyarakat dan organisasi, kegiatan ini merupakan alat masyarakat setempat untuk memenuhi kebutuhannya dan bagi organisasi untuk mencapai tujuannya.

Hal tersebut sesuai dengan yang dikemukakan oleh Azrul Azwar (Ketua Kwartir Nasional), kepramukaan bertujuan untuk mendidik anakanak dan pemuda Indonesia dengan prinsip-prinsip dasar dan metode 
kepramukaan yang pelaksanaannya disesuaikan dengan keadaan, kepentingan, dan perkembangan bangsa serta masnyarakat Indonesia.

Menurut Tomas Lickona dalam buku Retno Listyarti,pendidikan karakter adalah perihal menjadi sekolah karakter, dimana sekolah menjadi tempat terbaik untuk menanamkan karakter. Adapun penanaman karakter itu sendiri itu didasarkan pada totalitas psikologis yang mencakup seluruh potensi individu manusia (kognitif, afektif, dan psikomotorik) dan fungsi totalitas sosiokultural dalam konteks interaksi dalam keluarga, satuan pendidikan dan masyarakat. Sedangkan menurut Koesoema dalam jurnal penelitian Marzuki dan Lyza Hapsari, karakter identik dengan kepribadian atau akhlak. Kepribadian merupakan ciri, karakter atau sifat khas diri seseorang yang bersumber dari bentukan-bentukan yang di terima dari lingkungannya.

Menurut Hudiyono Kata religius merupakan sebuah sikap dan perilaku yang patut dalam melaksanakan ajaran agama yang dianutnya, toleransi terhadap pelaksanaan ibadah agama lainnya, serta hidup rukun dengan agama lain. Konsep Islam dalam sistem nilai kereligiusan mencakup tiga komponen nilai yaitu: nilai aqidah, nilai ibadah dan nilai akhlak, namun dalam penelitian ini difokuskan pada pengamalan nilai ibadah dan nilai akhlak.

Pendidikan kepramukaan yang dianggap masih melakukan kegiatan dengan cara-cara sederhana namun manfaat dari kegiatan tersebut sangat besar dalam membentuk karakter peserta didik yang belum tentu diperoleh dari pendidikan formal. Pihak siswa sendiri banyak yang kurang berminat terhadap kegiatan pramuka, itu disebabkan orientasi belajar siswa terfokus pada orientasi nilai pada pelajaran-pelajaran umum terutama pelajaran yang diujikan. Sehingga para siswa yang berorientasi demikian menganggap kegiatan pramuka sebagai kegiatan tambahan yang kurang penting. Hal ini disebabkan siswa belum memahami nilai-nilai di balik kesederhanaan yang tetap dipertahankan dalam kegiatan pramuka yang diselenggarakan hingga saat ini. Padahal dibalik kesederhanaan pramuka 
tersebut apabila dipahami secara sungguh-sungguh dapat mengantar siswa pada pengembangan potensi (life skill) yang dimiliki siswa berkaitan dengan nilai-nilai agama Islam yang terkandung dalam Dhasa Darma Pramuka. Kecerdasan bukan hanya terletak pada penguasaan ilmu pengetahuan semata, namun juga harus ditopang oleh jasmani yang kuat, keterampilan dan juga moral, yang semua itu dapat diperoleh melalui kegiatan pramuka, melalui gerakan pramuka generasi muda sehingga dapat membentuk karakter bangsa.

\section{METODE PENELITIAN}

Penelitian ini menggunakan penelitian kuantitatif. Dalam hal ini jenis penelitian yang dilakukan adalah ex-post facto. Tujuan penelitian ex-post facto yaitu untuk menemukan penyebab yang memungkinkan perubahan perilaku, gejala atau fenomena yang disebabkan bebas yang secara keseluruhan sudah terjadi. Penelitian ini dilaksanakan di Madrasah Ibtidayah Datok Sulaiman Palopo, yaitu Madrasah Ibtidaiyah yang berada di dalam kompleks Pesantren Modern Datok Sulaiman kampus Putra Balandai Palopo, Provinsi Sulawesi Selatan.

Dengan subjek penelitian adalah anggota pramuka yang berjumlah 30 siswa dengan rincian 12 siswa kelas IV, 13 siswa kelas V dan 13 siswa kelas VI. Data yang terkumpul dalam penelitian ini adalah data keaktifan anggota pramuka dalam mengikuti kegiatan kepramukaan dan karakter religius untuk memperoleh data tersebut digunakan teknik pengumpulan data berupa observasi, angket dan wawancara. Analisis data yang digunakan dalam penelitian ini ada 3 tahap, yaitu analisis uji instrument, analisis statistik deskripsi dan analisis statistik.

Pada penelitian ini ada satu instrumen yang digunakan yaitu angket. Angket digunakan untuk mengetahui karakter religius siswa berdasarkan kegiatan pendidikan Kepramukaan. Instrumen yang baik harus valid dan reliabel. Untuk mencari validitas angket menggunakan validitas isi berupa 
lembar validasi dengan bantuan validator yaitu pembina pramuka dan dosen. Selanjutnya dilakukan validitas item dan uji reliabilitas instrumen.

Analisis data deskriptif berupa angket karakter religius anggota pramuka MI Datok Sulaiman Palopo, hasil belajar pendidikan kepramukaan anggota pramuka MI Datok Sulaiman Palopo dan hasil wawancara diolah dengan menggunakan software IBM Statistic Version 22, setelah diperoleh data nilai angket dan data nilai hasil belajar kepramukaan siswa maka data tersebut terlebih dahulu diuji kenormalan dan homogenitasnya

\section{HASIL PENELITIAN}

Setelah peneliti melakukan penelitian pengaruh pendidikan kepramukaan terhadap pembentukan karakter religius terhadap pembentukan karakter religius anggota pramuka MI Datok Sulaiman bagian putra Palopo, dapat diketahui bahwa terdapat pengaruh signifikan Hal tersebut dapat diketahui berdasarkan hasil observasi yang dilakukan dan hasil analisis data yang dilakukan mulai dar analisis uji instrument, analisis deskripsi dan analisis regresi linear sederhana.

Berdasarkan hasil analisis data yang dilakukan diketahui bahwa terdapat pengaruh yang signifikan antara pendidikan kepramukaan terhadap pembentukan karakter religius anggota pramuka Madrasah Ibtidaiyah Datok Sulaiman Bagian Putra Palopo. Hasil konsultasi dengan tabel interpretasi koefisien korelasi nilai $r$ sebesar 0,631 menunjukkan korelasi kuat. Dan besar persentase pengaruh pendidikan kepramukaan terhadap pembentukan karakter religius sebesar 39,8\% sedangkan sisanya $60,2 \%$ ditentukan oleh variabel lain.

\section{PEMBAHASAN}

Pembahasan berisi ringkasan hasil penelitiannya, keterkaitan dengan konsep atau teori dan hasil penelitian lain yang relevan, interpretasi temuan, keterbatasan penelitian, serta implikasinya terhadap perkembangan konsep atau keilmuan. 
Pembahasan pokok ini adalah pengaruh kegiatan pendidikan kepramukaan yang tergambarkan pada point dasa dharma terhadap karakter religius yang difokuskan pada pengamalan ibadah dan akhlak anggota pramuka MI Datok Sulaiman bagian putra Palopo.

Melalui pendidikan kepramukaan akan membentuk karakter anggota pramuka salah satunya yaitu karakter religius yang difokuskan pada hal ibadah dan akhlak. Kegiatan-kegiatan sederhana kepramukaan yang dilakukan anggotanya akan memberikan pengalaman dan pembelajaran yang dikemas dalam bentuk sederhana seperti pada kegiatan membuat kerangka tenda yang dalam pelaksanaannya sesuai dengan nilai-nilai Dasa Dharma.

Penerapan pelaksanaan pendidikan kepramukaan di sekolah terkhusus Madrasah akan berpengaruh pada siswa dalam hal pembentukan karakter. Tujuan kepramukaan salah satunya adalah membentuk karakter siswa selaras dengan tujuan kurikulum pendidikan itu sendiri. Kegiatan kepramukaan yang dikemas dalam bentuk belajar dan bermain pada tingkat siaga/SD akan lebih menarik minat siswa dan dapat membentuk menanamkan nilai-nilai karakter secara tidak langsung.

Hasil penelitian ini menunjukkan bahwa terdapat pengaruh signifikan antara pendidikan kepramukaan terhadap pembentukan karakter religius dalam hal ibadah dan akhlak anggota pramuka MI Datok Sulaiman bagian Putra Palopo.

Nilai hasil belajar pendidikan kepramukaan anggota pramuka MI Datok Sulaiman Palopo dapat dilihat pada diagram berikut: 


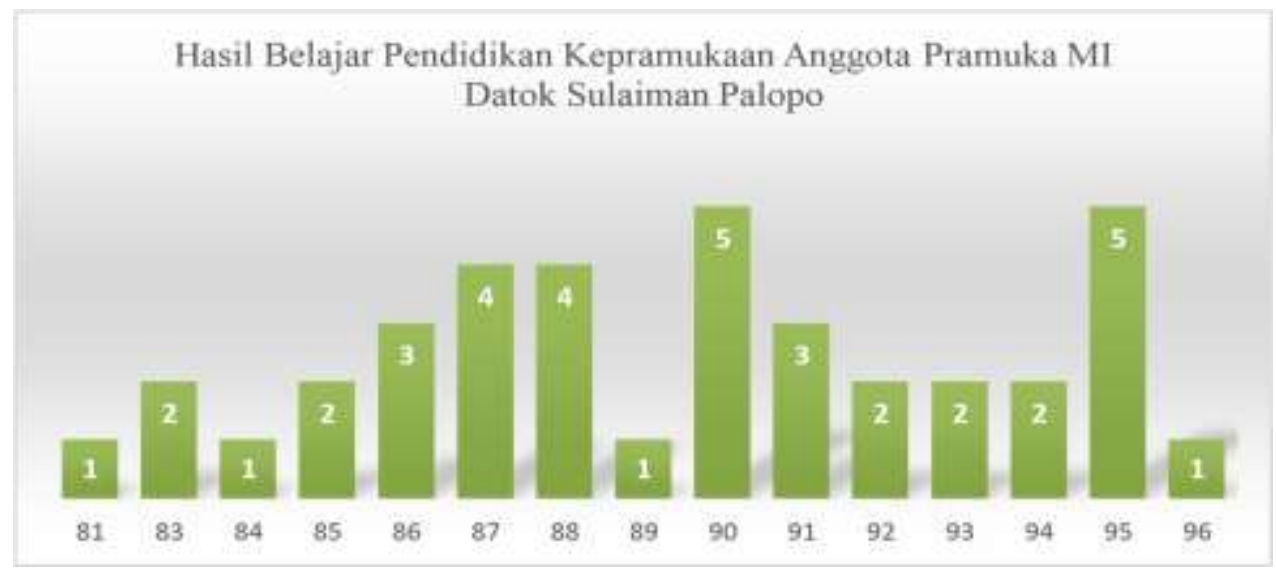

Gambar 1. Indonesian Journal of Educational Review

Berdasarkan diagram di atas terlihat bahwa nilai bahwa nilai pendidkan kepramukaan anggota pramuka baik terlihat dari perolehan nilai 38 anggota pramuka MI Datok Sulaiman Palopo, nilai 81, 84, 89, 96 masingmasing sebanyak 1 orang. Nilai 83, 85, 92, 93, 94 masing-masing sebanyak 2 orang. Nilai 86 dan 91 masing-masing sebanyak 3 orang. Nilai 87 dan 88 masing-masing sebanyak 4 orang. Serta nilai 90 dan 95 masing-masing sebanyak 5 orang.

Berdasarkan analisis angket pembentukan karakter religius dengan materi pernyataan berdasarkan kegiatan kepramukaan yang sesuai dengan pont-point dasa Dharma yang diberikan kepada 38 anggota pramuka diperoleh bahwa karakter religius dalam hal ibadah dan akhlak anggota pramuka MI Datok

Sulaiman bagian putra mempunyai karakter yang baik. Terlihat ini dapat dilihat dari jawaban angket siswa, di mana untuk pernyataan positif lebih banyak memilih jawaban sering sekali dan sering. Sedangkan untuk pernyataan negatif juga lebih banyak memilih alternatif jawaban tidak pernah.

Berdasarkan analisis regresi linear sederhana diperoleh Hasil konsultasi dengan tabel interpretasi koefisien korelasi nilai $r$ sebesar 0,631 menunjukkan korelasi kuat. Dengan demikian dapat diketahui bahwa variabel pendidikan kepramukaan anggota pramuka Madrasah Ibtidaiyah Datok Sulaiman bagian putra Palopo $(X)$ memiliki pengaruh yang sangat 
kuat terhadap karakter religius anggota pramuka Madrasah Ibtidaiyah Datok Sulaiman Palopo (Y).

Agar mengetahui besar kecilnya pengaruh variabel pendidikan kepramukaan terhadap pembentukan karakter religius anggota pramuka Madrasah Ibtidaiyah Datok Sulaiman Palopo dapat ditentukan dengan rumus koefisien determinan dengan hasil $: K P=r 2 \times 100 \%=39,8 \%$. Artinya pengaruh pendidikan kepramukaan terhadap pembentukan karakter religius anggota pramuka Madrasah Ibtidaiyah Datok Sulaiman Bagian Putra Palopo sebesar 39,8\% sedangkan sisanya 60,2\% ditentukan oleh variabel lain. Variabel lainnya yang mempengaruhi karakter religius anggota pramuka Madrasah Ibtidaiyah Datok Sulaiman Palopo dapat berupa faktor internal maupun faktor eksternal .

\section{KESIMPULAN}

Berdasarkan hasil penelitian yang telah dilakukan. Maka dapat disimpulkan sebagai berikut:

1) Berdasarkan hasil analis data menggunakan software IBM Statistic Version 23 diperoleh skor rata-rata $(\mu)$ hasil belajar pendidikan kepramukaan anggota pramuka MI Datok Sulaiman Bagian Putra Palopo adalah sebesar 89,4737 dari skor ideal 100 dengan standar deviasi $(\sigma)=3,95062$ dan variansi $\left(\sigma^{2}\right)=15,607$. Skor tertinggi $($ maksimum $)=96$ dan skor terendah $($ minimum $)=81$ dengan range $=15$.

2) Sebagian besar anggota pramuka MI Datok Sulaiman Bagian Putra Palopo mempunyai karakter religius yang baik. Hal ini dapat dilihat dari jawaban angket siswa, di mana untuk pernyataan positif lebih banyak memilih jawaban sering sekali dan sering. Sedangkan untuk pernyataan negatif juga lebih banyak memilih alternatif jawaban tidak pernah.

3) Terdapat pengaruh yang signifikan antara pendidikan kepramukaan terhadap pembentukan karakter religius anggota pramuka Madrasah 
Ibtidaiyah Datok Sulaiman Bagian Putra Palopo. Hasil konsultasi dengan tabel interpretasi koefisien korelasi nilai $r$ sebesar 0,631 menunjukkan korelasi kuat. Dengan demikian dapat diketahui bahwa variabel pendidikan kepramukaan anggota pramuka Madrasah Ibtidaiyah Datok Sulaiman Palopo (X) memiliki pengaruh yang kuat terhadap karakter religius anggota pramuka Madrasah Ibtidaiyah Datok Sulaiman Palopo (Y). Pengaruh pendidikan kepramukaan terhadap pembentukan karakter religius anggota pramuka Madrasah Ibtidaiyah Datok Sulaiman Bagian Putra Palopo sebesar 39,8\% sedangkan sisanya $60,2 \%$ ditentukan oleh variabel lain.

Berdasarkan hasil yang diperoleh dalam penelitian ini maka peneliti menyarankan beberapa hal sebagai berikut: 1) Bagi siswa, dibutuhkan kesadaran dan kerja samanya dalam mengikuti kegiatan kepramukaan sehingga karakter religius anggota pramuka dapat lebih maksimal. 2) Pendidikan kepramukaan dapat menjadi salah satu alternatif dalam meningkatkan karakter religius anggota pramuka.3) Melihat hasil penelitian yang diperoleh dari pendidikan kepramukaan yang diterapkan diharapkan menjadi referensi dalam meningkatkan karakter religius anggota pramuka.4) Kepada para peneliti di bidang pendidikan, agar mengadakan penelitian lebih lanjut mengenai pembelajaran pendidikan Kepramukaan terhadap pembentukan karakter religius anggota pramuka dengan materi yang lebih beragam dan lebih baik lagi, sebagai salah satu upaya peningkatan karakter siswa.

\section{DAFTAR PUSTAKA}

[1] Ali Gunawan, Muhammad. 2013. Statistik untuk Penelitian Pendidikan, Cet. I; Yogyakarta: Parama Publishing

[2] Arikunto, Suharsimi. 2012. Dasar-Dasar Evaluasi Pendidikan, Cet. I Edisi Kedua; Jakarta: PT Bumi Aksara.

[3] Azwar, Azrul. 2013.Mengenal Pramuka Cet. I Jakarta: Esensi Erlangga Group, 2012. 
[4] Bob Sunardi, Andri. Boyman Ragam Latih Pramuka, Cet. VIII; Bandung; PT Nuansa Muda.

[5] Departemen Pendidikan dan Kebudayaan. 1995.Kamus Besar Bahasa Indonesia, (Cet. IV; Jakarta: Balai Pustaka.

[6] Direktorat Jenderal Pendidikan Islam Departemen Agama RI. 2006.Undangundang dan Peraturan Pemerintah RI tentang Pendidikan, Jakarta: Direktorat Jenderal Pendidikan Islam Departemen Agama RI

[7] Hudiyono, 2012. Membangun Karakter Siswa melalui Profesionalisme Guru dan Gerakan Pramuka. Jakarta: Esensi Erlangga Group.

[8] Kesuma, Dharma dkk, 2013.Pendidikan Karakter Kajian Teori dan Praktek di Sekolah, Cet. IV; Bandung: PT Rosdakarya

[9] Listyarti, Retno.2013. Pendidikan Karakter dalam metode Aktif, linovatif dan Kreatif, Jakarta: Erlanggax.

[10] Marzuki dan Lyza Hapsari. Pembentukan Karakter Siswa Melalui Kegiatan

[11] Kepramukaan di MAN 1 Yogyakarta Jurnal Pendidikan Karakter Edisi V,

[12] No.2, Oktober 2005. Di ambil dari: https://journal.uny.ac.id/index.php/jpka/article/view/8619.

[13] Sholeh dkk, Muhammad. Analisis Kualitas Layanan Website BTKP-DIY

[14] Menggunakan Metode Webqual 4.0 Jurnal JORKAM Volume 1, No.2

[15] Januari 2014. Di ambil dari :

[16] http://download.portalgaruda.org/article.php?article=293176\&val=6284\&t itle=ANALISIS\%20KUALITAS\%20LAYANAN\%20WEBSITE\%20BTK PDIY\%20MENGGUNAKAN\%20METODE\%20WEBQUAL\%204.0.

[17] S.Margono, 2014. Penelitian Pendidikan, Cet. IX; Jakarta: Rineka Cipta, 2014.

[18] Ummah M.T, Khairul. Kami Pramuka Indonesia (Cet. I Sidoarjo: PT Masmedia Buana Pustaka. 